\title{
Philocorydoras longus sp. n. (Monogenea, Dactylogyridae) from the gills of Hoplosternum littorale (Siluriformes, Callichthyidae) in Southeastern Brazil and the reassignment of two species from the genus Urocleidoides to Philocorydoras
}

\author{
F. H. YAMADA*, H. BRANDÃO, P. DE. O. F. YAMADA, R. J. DA SILVA
}

UNESP - Univ Estadual Paulista, Campus de Botucatu, Instituto de Biociências, Departamento de Parasitologia, Botucatu, São Paulo, Brazil, *E-mail: fhyamada@hotmail.com

\section{Article info}

Received February 6, 2014 Accepted August 13, 2015

\begin{abstract}
Summary
Philocorydoras longus sp. n. (Dactylogryridae) is described from the gills of the freshwater fish HopIosternum littorale (Hancock, 1828) (Callichthyidae) from Jurumirim reservoir, Upper Paranapanema River, São Paulo State, Brazil. This new species belongs to the genus Philocorydoras mainly by possessing a curved cirrus accompanied by an accessory piece attached by a conspicuous filament. Philocorydoras longus sp. n. most resembles $P$. platensis, but differs by having delicate and smaller hooks, grooves in ventral and dorsal anchors, larger cirrus and accessory piece, and ventral bar with a long postero-medial process. Two species of the genus Urocleidoides (U. corydori Molnar, Hanek et Fernando, 1974 and U. margolisi Molnar, Hanek et Fernando, 1974) originally described from the gills of Corydoras aeneus (Gill, 1858) from Talparo River, Trinidad (near Brazil), were transferred to the genus Philocorydoras mostly by the absence of a sinistral vaginal sclerite (i. e., the primary characters of Urocleidoides) and counterclockwise cirral rings (i.e., curved tube, and tapered anteriorly in Philocorydoras). The new species is the fourth species assigned to the genus and the first recorded for Brazil.
\end{abstract}

Keywords: Ancyrocephalinae; Freshwater fish; Neotropical region; Paranapanema river

\section{Introduction}

The Siluriformes is a very large fish group, widely distributed across the tropical regions of the world. Hoplosternum littorale (Hancock, 1828) is a callichthyid armoured catfish of freshwater ecosystems from South America (Reis, 1997). The first record of monogeneans parasitizing this fish species was made by Pavanelli et al. (2004), but they did not identify the species.

To date, Gyrodactylus von Nordmann, 1832 and Philocorydoras Suriano, 1986 are the two known monogenean genera found on callichthyid armoured catfishes in the Neotropical region (see Cohen et al., 2013). The genus Philocorydoras was originally proposed for gill monogeneans of Corydoras paleatus (Jenyns, 1842) in Laguna Chascomús, Argentina. The genus is characterized by possessing a sclerotized curved cirrus and accessory piece attached to the base of the cirrus by a conspicuous filament (see Suriano, 1986).

The purpose of the present paper is to describe a new species of Philocorydoras from $\mathrm{H}$. littorale in Upper Paranapanema River, São Paulo State, Brazil, and elucidate the taxonomic status of Urocleidoides corydori and U. margolisi.

\section{Materials and methods}

Twenty-two specimens of $H$. littorale (Standard length range: 10.60 - $16.00 \mathrm{~cm}$ ) were collected between April 2011 and July 2012 from Jurumirim reservoir (2312'17"S; 49¹3'19"W), Upper Paranapanema River, Municipality of Taquarituba, São Paulo State, Brazil. Gills were removed and placed in vials containing $5 \%$ formalin solution. Parasites were stored in $70 \%$ ethanol solution. Some specimens were mounted unstained in Hoyer's medium in order to study the sclerotized structures. Specimens stained with Gomori's trichrome were used to observe internal organs (Eiras et al., 2006). Measurements are in micrometers and expressed as the mean \pm standard deviation followed by range in parentheses. Landmark definition and morphometric measurements of haptor 


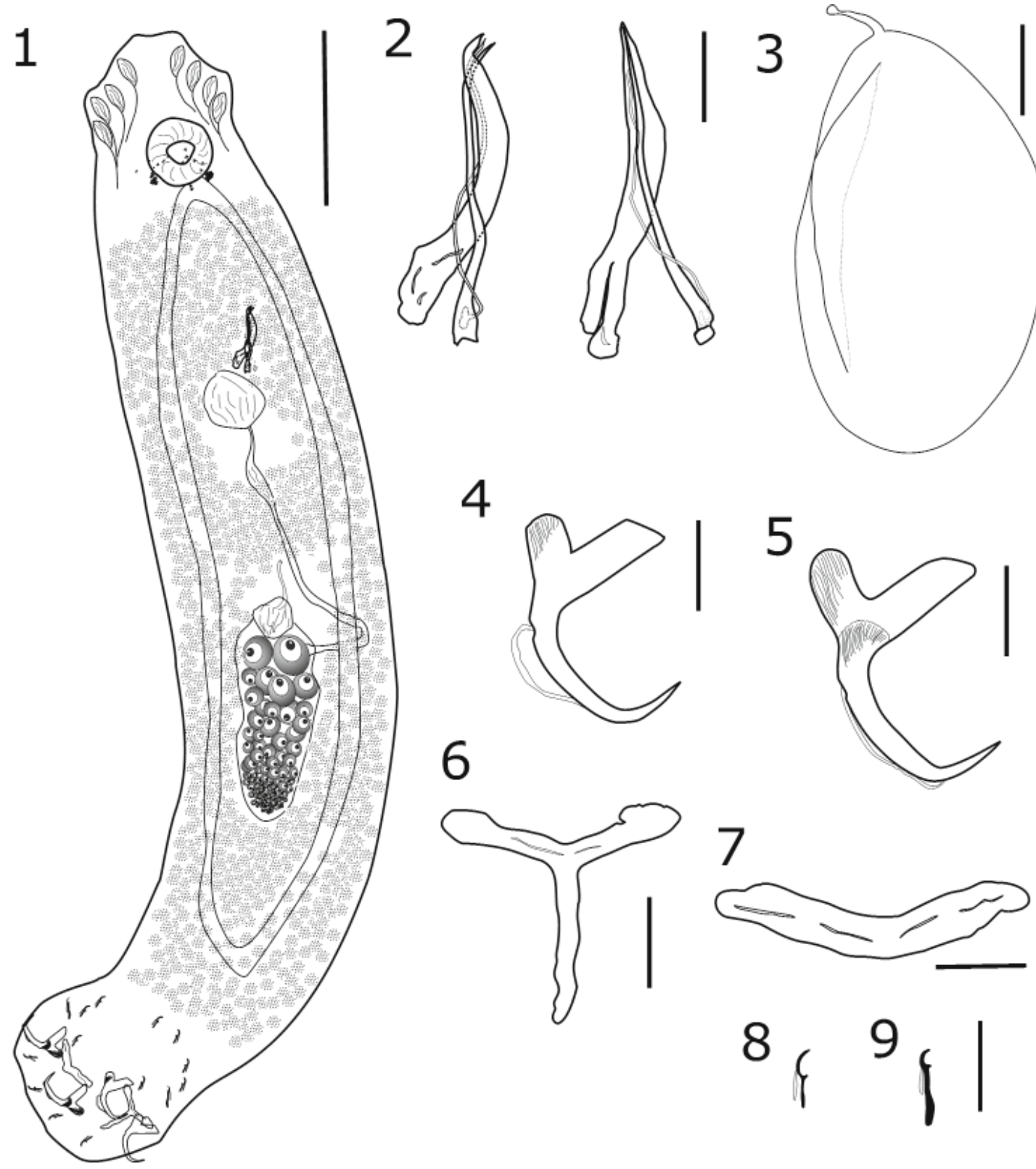

Figs. 1 - 9. Philocorydoras longus sp. n., line drawings. (1) Composite drawing of whole-mount, ventral view; (2) Copulatory complex, ventral view; (3) Egg; (4) Ventral anchor; (5) Dorsal anchor; (6) Ventral bar; (7) Dorsal bar; (8) Hook pairs 1, 2, 3, 5, 6, 7; (9) Hook pair 4. Scale bars: Fig. $1=200 \mu \mathrm{m}$, Figs. $2-9=20 \mu \mathrm{m}$

sclerotized parts [total length of anchor (a), length of base (b), length of inner root $(c)$, length of outer root (d), length of point (e); total length of marginal hook $(\mathrm{f})$; total length of bar $(\mathrm{g})$, total width (h); median width (i)] are in accordance with Gussev (1985). Numbering and distribution of hook pairs follows Mizelle (1936). Specific terminology to genus Philocorydoras follows Suriano (1986). Type specimens are deposited in the helminthological collections of the Instituto Oswaldo Cruz (CHIOC), and the Instituto de Biociências de Botucatu (CHIBB), both in Brazil.

\section{Results}

Philocorydoras longus sp. $\mathrm{n}$.

(Figs. 1-9)

Description (measurements based on 15 adult specimens): Body elongate, fusiform, $951 \pm 276$ (644 - 1463) long; maximum width $211 \pm 47(146-300)$ near mid-length or anterior half of body (Fig. 1). Four cephalic lobes and two eyespots present; eye granules small, generally elongate; accessory granules sparse in cephalic region. Pharynx spherical $65 \pm 15(51-100)$ in diameter; oesophagus absent. Peduncle broad; haptor rectangular $151 \pm 8$ (145 - 157) long, $210 \pm 7(205-215)$ wide. Ventral anchor: (a) 48 \pm 2 (45 - 52); (b) $45 \pm 1$ (43 - 47); (c) $20 \pm 2$ (18 - 23); (d) $12 \pm 1$ (10 - 14); (e) $18 \pm 2$ (15 - 24), roots well defined, deep root with grooves, elongate shaft and short tip (Fig. 4). Dorsal anchor: (a) $50 \pm 2$ (46 - 52); (b) $45 \pm 1$ (43 - 47); (c) $22 \pm 2$ (19 - 24); (d) 13 $\pm 2(10-16)$; (e) $18 \pm 2(16-20)$, roots well defined, deep root with grooves, grooves between roots and shaft, elongate shaft and short tip (Fig. 5). Ventral bar: (g) $58 \pm 8$ (49 - 73); (h) $45 \pm 6$ (36 -57); (i) $6 \pm 1$ (5 - 7), T-shaped, with a postero-medial projection 
11

10

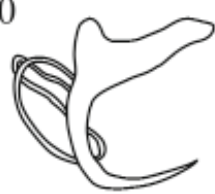

12

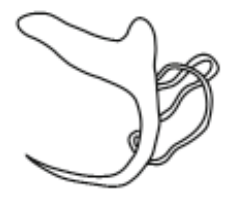

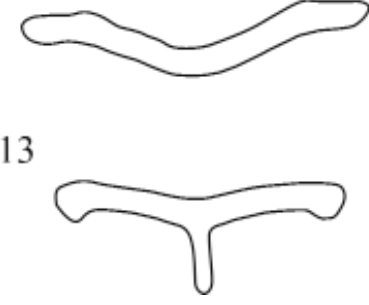

17

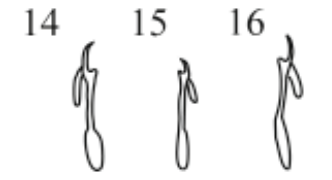

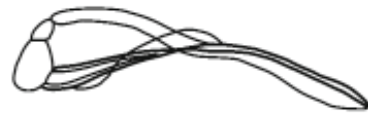

18

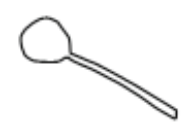

Figs. 10 - 18. Philocorydoras corydori (Molnar, Hanek et Fernando, 1974) comb. n., line drawings. (10) Dorsal anchor; (11) Ventral anchor; (12) Dorsal bar; (13) Ventral bar; (14) Hook pairs 2, 3, 4, 6; (15) Hook pairs 1, 5; (16) Hook pair 7; (17) Copulatory complex; (18) Vagina (drawing adapted from Molnar et al., 1974). Scale bar $=40 \mu \mathrm{m}$

(Fig. 6). Dorsal bar: (g) $60 \pm 7(48-73)$; (h) $21 \pm 5(15-33)$; (i) $9 \pm 2(6-14)$, yoked-shaped, with tapered ends (Fig. 7). Hook pairs 1, 2, 3, 5, 6 and 7 similar, (f) $11 \pm 1(10-12)$ long, each with elongate point, upright thumb, uniform shank, filament hook loop 2/3 shank length (Fig. 8); hook pair 4, (f) $15 \pm 2$ (14 - 18) long, with short point, upright thumb, shank with distal portion inflated, filament hook loop 1/3 shank length (Fig. 9). Cirrus an arced tube, straight, $70 \pm 4$ (66 - 77) long (Fig. 2). Accessory piece $74 \pm 10$ (58 - 96) long, expanded anteriorly, sclerotized, non-articulated to base of cirrus (Fig. 2). Copulatory ligament originated at the base of cirrus and linked to accessory piece. An unsclerotized mid-ventral vagina, with delicate tube leading to seminal receptacle. Gonads overlapping. Seminal vesicle elongate and a dilatation of vas deferens. Oviduct, ootype and uterus not observed. Vitelline follicles dense, dispersed throughout trunk, absent in region of reproductive organs and MCO. Eggs oval $92 \pm 7$ (87 - 97) long, 59 $\pm 0.5(58-59)$ wide, with appendage (Fig. 3).

\section{Taxonomic summary}

Type host: Hoplosternum littorale (Hancock, 1828) (Siluriformes, Callichthyidae).

Type locality: Jurumirim reservoir, Upper Paranapanema River (2312'17'S; 49¹3'19'W), Municipality of Taquarituba, São Paulo State, Brazil.

Site of infection: Gill filaments.

Type specimens: Holotype, CHIOC 38205; paratypes, CHIOC 38206 and CHIBB 138L and 139L

Prevalence: $50 \%$ (11 of 22 fishes examined).

Mean intensity of infection: 9.27 parasites per parasitized host.
Etymology: The new species is from Latin (longus = elongated) and is derived from the presence of an elongated projection in ventral bar.

\section{Remarks}

Philocorydoras longus sp. $\mathrm{n}$. belongs to the genus Philocorydoras by having a curved cirrus tube, tapered anteriorly, accompanied by an accessory piece attached to the base of the cirrus by a copulatory ligament. The new species most resembles $P$. platensis but it differs from this latter species by having delicate and smaller hooks (10-18 vs. 15-30), grooves in ventral and dorsal anchors, larger cirrus (mean 70 vs. 40) and accessory piece (mean 74 vs. 35 ), ventral bar with a long postero-medial process (mean 45 vs. 18). Suriano (1986) in the original description of the genus did not mention the presence of grooves in both anchors. The new species has grooves in the deep root of ventral anchors, and in the deep root and between shaft and root of dorsal anchors. The tip of both anchors of $P$. longus sp. $\mathrm{n}$. does not exceed the level of the superficial root as opposed to $P$. platensis. Philocorydoras platensis has hook pairs 1 and 2 smaller than others, whereas in the new species hook pairs 1, 2, 3, 5, 6 and 7 are smaller than hook pair 4 .

Philocorydoras corydori (Molnar, Hanek et Fernando, 1974) comb. n. Synonym: Urocleidoides corydori Molnar, Hanek et Fernando, 1974

(Figs. $10-18$ )

Description (based on Molnar et al., 1974): Body fusiform, cuticle smooth, thin. Prohaptor area obscure. Eyes two. Peduncle short.
19

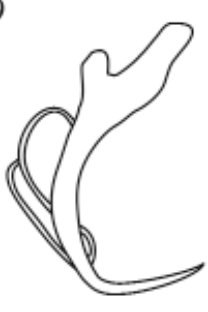

20

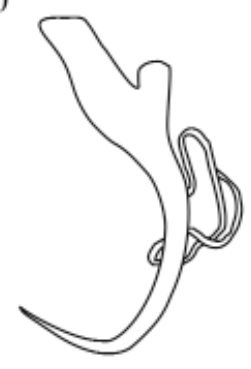

21

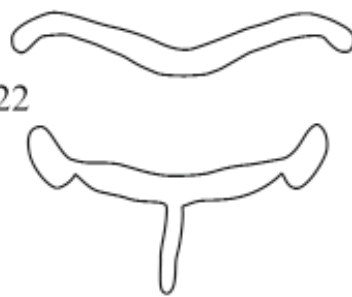

23

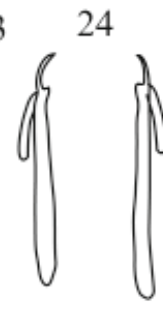

25

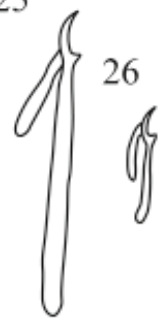

27

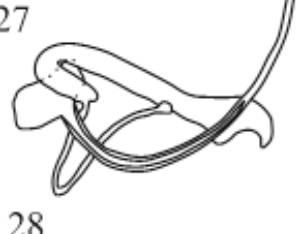

28

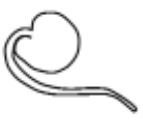

Figs. 19 - 28. Philocorydoras margolisi (Molnar, Hanek et Fernando, 1974) comb. n., line drawings. (19) Dorsal anchor; (20) Ventral anchor; (21) Dorsal bar; (22) Ventral bar; (23) Hook pair 1; (24) Hook pairs 2, 3, 6, 7; (25) Hook pair 4; (26) Hook pair 5; (27) Copulatory complex; (28) Vagina (drawing adapted from Molnar et al., 1974). Scale bar $=40 \mu \mathrm{m}$ 
Haptor subquadrate. Dorsal and ventral anchors simple and well developed superficial roots. Dorsal bar V-shaped, ends directed laterally. Ventral bar straight, slightly enlarged ends, with a postero-medial projection. Hooks similar in shape. Cirrus a straight curved tube, tapered anteriorly. Accessory piece a simple bar parallel to and articulated with cirrus. Copulatory ligament present. Parasites of gills of Corydoras aeneus (type host) from Talparo River, Trinidad (type locality).

Philocorydoras margolisi (Molnar, Hanek et Fernando, 1974) comb. n.

Synonym: Urocleidoides margolisi Molnar, Hanek et Fernando, 1974

(Figs. 19-28)

Description (based on Molnar et al., 1974): Body fusiform, cuticle smooth, thin. Prohaptor with two cephalic lobes. Eyes two. Haptor subquadrate. Dorsal and ventral anchors slender, well-developed roots, possessing a conspicuous anchor filament. Dorsal bar V-shaped with laterally directed ends. Ventral bar straight, enlarged ends, with a posteromedial projection. Hooks similar in shape. Cirrus curved tube and tapered anteriorly. Accessory piece distally sickle-shaped and articulated with cirrus. Copulatory ligament present. Egg flattened on one side. Parasites of gills of $C$. aeneus (type host) from Talparo River, Trinidad (type locality).

\section{Remarks}

Philocorydoras corydori comb. n. and P. margolisi comb. n. closely resemble others members of Philocorydoras by having a curved cirrus tube, accompanied by an accessory piece attached to the base of the cirrus by a copulatory ligament (see Suriano, 1986), as well as the morphology of dorsal (i.e., yoked-shaped) and ventral bars (i.e., T-shaped, with a postero-medial projection). Both species differs from $P$. platensis and $P$. longus sp. n. by the accessory piece articulated with cirrus base. Philocorydoras margolisi comb. n. can be distinguished from its congeners by having accessory piece with sickle-shaped terminal portion bent; ventral and dorsal anchors slender; and hooks more robust than the other species.

\section{Discussion}

To date, only the type species (P. platensis) of Philocorydoras has been described in South America. Kritsky et al. (2000) suggested a relationship of the genus Philocorydoras with Vancleaveus Kritsky, Thatcher, et Boeger, 1986, and Ameloblastella Kritsky, Mendoza-Franco, et Scholz, 2000. These three genera possess overlapping gonads, ventral bar with a medial process, hook shanks comprised of two subunits, subspherical eye granules, and dilatation of the vas deferens to form the seminal vesicle. Philocorydoras differs from both Vancleaveus and Ameloblastella by having an arced tube cirrus (Kritsky et al., 2000), and the presence of one pair of eyespots. Ameloblastella and Philocorydoras have some similarities like a copulatory ligament, and hooks with shank comprising two subunits. These genera parasitize fish species within the Siluriformes.
Molnar et al. (1974) described two species of monogeneans parasitizing C. aeneus (Gill, 1858) from Talparo River, Trinidad (near Brazil), as belonging to the genus Urocleidoides ( $U$. corydori and U. margolisi ). Suriano (1986) and Kritsky et al. (1986) pointed out that these species do not belong to the genus Urocleidoides mostly by the absence of a sinistral vaginal sclerite and counterclockwise cirral rings. Furthermore, these species were considered incertae sedis by Kritsky et al. (1986). The anatomy of the male copulatory organ do not belong to the genus Urocleidoides (i.e. cirrus coil counterclockwise), and it is more related to the genus Philocorydoras. Kritsky et al. (2000) based on the comparative morphology of the male copulatory organ suggests that both species should be transferred to Philocorydoras; however, they did not transfer them because the lacking of details of the internal anatomy. Philocorydoras longus sp. $\mathrm{n}$. has an accessory piece attached to the base of the cirrus by a conspicuous filament as $P$. corydori comb. $\mathrm{n}$. and P. margolisi comb. n. However, the new species differs from this latter species by having the accessory piece not articulated with the cirrus base. Philocorydoras longus sp. $\mathrm{n}$. and $P$. corydori comb. n. resemble in the morphometry of hooks, however smaller than $P$. margolisi comb. n. According to Kaci-Chaouch et. al. (2008), the morphometric intraspecific variability within monogeneans would be a consequence of host specificity, i.e. the more a parasite species uses different host species, the more its intraspecific variance increases. All known species of Philocorydoras are gills parasites of callichthyids. Therefore, all the features mentioned above justify the transference of $U$. corydori and $U$. margolisi to Philocorydoras

\section{Acknowledgments}

The authors thank the Fundação de Amparo à Pesquisa do Estado de São Paulo/FAPESP (2011/22603-3, 2014/14298-4 and 2013/25786-7) for the scholarship granted to FHY and POFY, Coordenação de Aperfeiçoamento Pessoal de Nível Superior/ CAPES (AUX-PE-PNPD 3005/2010), to the staff of the Laboratório de Biologia e Ecologia de Peixes, and the Universidade Estadual Paulista/UNESP for the facilities offered for the development of this work.

\section{References}

Cohen, S.C., Justo, M.C., Kohn, A. (2013): South American Monogenoidea parasites of fishes, amphibians and reptiles. Rio de Janeiro, BR, Oficina de livros, 663 pp.

Eiras, J.C., Takemoto, R.M., Pavanelli, G.C. (2006): Métodos de estudo e técnicas laboratoriais em parasitologia de peixes. $3^{\text {rd }}$ Edition, Maringá, BR, Eduem, 199 pp.

Gussev, A.V. (1985): Monogenea. In: BAUER, O.N. (Eds) Key to parasites of the freshwater fish fauna of the USSR. Vol. 2. Leningrad, USSR: Nauka Publications, pp. 87 - 99.

Kaci-Chaouch, T., Verneau, O., Desdevises, Y. (2008): Host specificity is linked to intraspecific variability in the genus Lamellodiscus (Monogenea). Parasitology, 135(5): 607 - 616. DOI: 10.1017/ S003118200800437X

Kritsky, D.C., Mendoza-Franco, E.F., Scholz, T. (2000): Neotropical Monogenoidea. 36. Dactylogyrids from the gills of Rhamdia 
guatemalensis (Siluriformes: Pimelodidae) from cenotes of the Yucatan Peninsula, Mexico, with proposal of Ameloblastella gen. $\mathrm{n}$. and Aplanoblastella gen. n. (Dactylogyridae: Ancyrocephalinae). Comp. Parasitol., 67(1): $76-84$

KRITSky, D.C., Thatcher, V.E., Boeger, W.A. (1986): Neotropical Monogenea. 8. Revision of Urocleidoides (Dactylogyridae, Ancyrocephalinae). Proc. Helminthol. Soc. Wash., 53(1): $1-37$

MizelLE, J.D. (1936): New species of trematodes from the gills of Illinois fishes. Am. Midl. Nat., 17(5): 785 - 806

Molnar, K., Hanek, G., Fernando, C.H. (1974): Ancyrocephalids (Monogenea) from freshwater fishes of Trinidad. J. Parasitol., $60(6): 914-920$
Pavanelli, G.C., Machado, M.H., Takemoto, R.M., Guidelli, G.M., LizAMA, M.A.P. (2004): Helminth fauna of fishes: diversity and ecological aspects. In: Thomaz, S.M., Agostinho, A.A., Hahn, N.S. (Eds) The Upper Paraná river and its Floodplain: physical aspects, ecology and conservation. Leiden: Backhuys Publishers, pp. 309 - 329 ReIS, R.E. (1997): Revision of the Neotropical catfish genus Hoplosternum (Ostariophysi, Siluriformes, Callichthyidae), with the description of two new genera and three new species. Ichthyol. Explor. Freshw., 7(4): 299 - 326.

SuRIano, D.M. (1986): Philocorydoras platensis gen. n. et sp. n. (Monogenea: Ancyrocephalidae) from Corydoras paleatus (Jenyns) (Pisces: Callichthyidae) in Laguna Chascomús - República Argentina. Helminthologia, 23: 249 - 256 